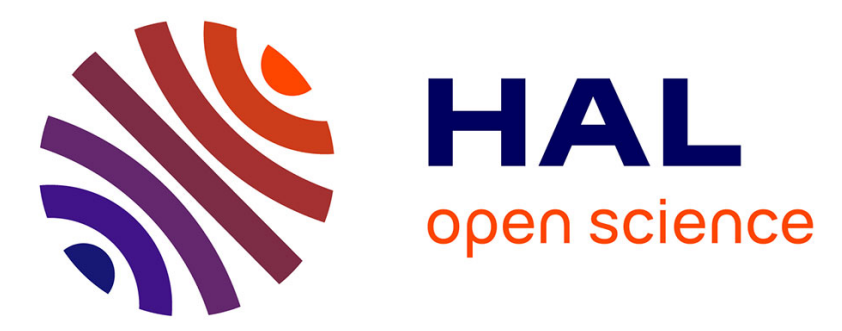

\title{
Isomerism in secondary bonded complexes: do structural rules apply?
}

M. Alikhani, Bernard Silvi

\section{To cite this version:}

M. Alikhani, Bernard Silvi. Isomerism in secondary bonded complexes: do structural rules apply?. International Journal of Quantum Chemistry, In press, 10.1002/qua.26670 . hal-03248403

\section{HAL Id: hal-03248403 \\ https://hal.science/hal-03248403}

Submitted on 3 Jun 2021

HAL is a multi-disciplinary open access archive for the deposit and dissemination of scientific research documents, whether they are published or not. The documents may come from teaching and research institutions in France or abroad, or from public or private research centers.
L'archive ouverte pluridisciplinaire HAL, est destinée au dépôt et à la diffusion de documents scientifiques de niveau recherche, publiés ou non, émanant des établissements d'enseignement et de recherche français ou étrangers, des laboratoires publics ou privés. 


\title{
Isomerism in secondary bonded complexes: do structural rules apply?
}

\author{
Alikhani M.E., Silvi B †‡
}

June 3, 2021

\begin{abstract}
The growing importance of secondary bonded complexes in modern coordination chemistry has given rise to an abundant literature in both experimental and theoretical coordination chemistry. We recently proposed an unified chemical model of secondary interaction enabling to understand the structures in terms of simple chemical rules and concepts. For some complexes the stoichiometry of the electrophilic moiety makes isomerism possible. The problems of isomerism and of the interconversion of isomers are addressed in the present. It is shown, that the reaction mechanisms discussed for pentacoordinated phosphorus derivatives are not suitable for complexes bound by a secondary interaction. The possibility of Berry's pseudo rotations is rejected for this class of systems.
\end{abstract}

forewords I met Istvan for the first time in 1987. It was during a visit I made in Budapest invited by my friend Angyan Janos. I remember, it was in winter, in the morning before lunch. I knew the scientific achievements of Istvan so I was very interested by the energy decomposition methods he was developing. I was eager to meet him and to discuss with him. I discovered a generous man, humble and enthusiastic. I was struck by his eyes where I could read his genuine benevolence and his spontaneous amazement behind the logic of the quantum chemistry he was working on. I had the opportunity to see him again during to scientific meeting I co-organized on Chemical bond, the first one held in La Colle sur Loup in 2000, the second seven years later in Manchester. Two years ago, I initiated a collective discussion paper on energy partitioning. Istvan participated to this project and his contributions to this paper are among the soundest and most salient. I will always remember him a engaging colleague from who I have learnt so much.

Bernard Silvi

${ }^{*}$ MONARIS UMR 8233 CNRS, Sorbonne Université, 4 place Jussieu, 75252 Paris Cedex 05, France

${ }^{\dagger}$ LCT UMR 7616, Sorbonne Université, 4 place Jussieu, 75252, Paris Cedex 05, France

${ }^{\ddagger}$ Corresponding author: sbernard@lct.jussieu.fr 


\section{Secondary interactions and isomerism}

The concept of secondary bond appeared in an article published by Alcock in $1972^{1}$, it refers to a class of interactions between non-metal atoms previously called "donor-acceptor" by Bent ${ }^{2}$. Secondary interactions are found in intermolecular complexes which have common structural features and whose complexation energies are usually less than $20 \mathrm{kcal} \mathrm{mole}^{-1}$. Although complexes involving secondary bonding are known for a century a significant effort has been during the last twenty years to finalize a classification ${ }^{3}$. Among secondary interaction we can mention the zoo of hydrogen bonds ${ }^{4}$ such as the classical and improper hydrogen bond ${ }^{5-8}$, double H-bonding ${ }^{9}$, and as well as non-covalent interactions known as triel ${ }^{10}$, tetrel $^{11}$, pnictogen ${ }^{12,13}$, chalcogen ${ }^{14}$, halogen ${ }^{15}$, and aerogen ${ }^{16,17}$ bonds. Recent publications have even distinguished the case of fluorine from the other halogens to form "F-Halogen Bond". ${ }^{18-20}$.

The stabilities and geometries of the complexes involving secondary interactions are currently explained by the theory of intermolecular forces ${ }^{21-30}$ because the interactions are considered to be weak. This perturbation based approach emphasizes the driving role of electrostatic interactions ${ }^{31,32}$, the anisotropy of which determines the angular geometry of the complex. The molecular electrostatic potential (MESP) of each moiety is often considered instead of the electrostatic energy itself. The concept of $\sigma$-hole has been introduced by Clark et $\mathrm{al}^{33}$ in order to provide a quantum chemical interpretation of the MESP maximum found on the halogen atom of the electron-acceptor (electrophilic) part of halogen bonded complexes. It was generalized further to other types of secondary interactions and, in a same fashion, $\pi$-holes have been introduced and invoked in the case of pnictogen ${ }^{34}$ and triel $^{35}$ bonds. We recently proposed a chemical model in which a secondary bonded complex is described as the precursor complex formed by the nucleophilic and electrophilic reactants of a hypothetical substitution or addition reaction ${ }^{36}$. It relies for an important part on a complementary application of the Rice and Teller's least motion principle ${ }^{37}$ and of the VSEPR rules ${ }^{38}$, an approach already successful for the understanding of hydrogen bonding ${ }^{39}$ and of reaction mechanism in organic chemistry ${ }^{40}$. Moreover, we proposed the use of the $f^{+}(\mathbf{r})$ Fukui function as an alternative to the molecular electrostatic potential as an indicator of the reactive regions around the electrophilic centre.

In the conclusion of the article cited above, we mentioned that the study of isomerism in secondary bonded complexes was an interesting topic worthy to develop. On the one hand, a given electrophilic molecule may contain several atomic centres likely to be involved in secondary interactions. For example, a molecule such as $\mathrm{PClH}_{2} \mathrm{O}$ may in principle form a pnictogen bond on the phosphorus centre or an halogen bond on the fluorine atom. Another possibility is the configuration isomerism around the electrophile centre which may occur for $\mathrm{AX}_{3}$ and $\mathrm{AX}_{4}$ type electrophile moieties provided the ligands of $\mathrm{A}$ are different enough. In the general case of Nuc $\cdots \mathrm{AL}^{1} \mathrm{~L}^{2} \mathrm{~L}^{3}$ there are two isomers forming a pair of enantiomers if the ligands $\mathrm{L}^{\mathrm{i}}$ are all different. The $\mathrm{Nuc} \cdots \mathrm{AL}^{1} \mathrm{~L}^{2} \mathrm{~L}^{3} \mathrm{~L}^{4}$ are expected to have trigonal bipyramidal shape with Nuc and the most electronegative ligand in axial position. If all ligands are different, there is a total of 20 isomers (10 pairs of enantiomers $)^{41}$. Krasowka et al have reviewed the stereochemistry of the structurally equivalent pentacoordinated phosphoranes ${ }^{42}$. Table 1 is an application of their table 1 . to the present complexes, it provides the 


\begin{tabular}{cc} 
general structure & number of chiral and achiral structures \\
\hline $\mathrm{A}\left(\mathrm{L}_{4}\right) \cdots \mathrm{Nuc}$ & 2 achiral \\
$\mathrm{A}\left(\mathrm{L}_{3}^{1} \mathrm{~L}^{2}\right) \cdots \mathrm{Nuc}$ & 2 achiral 2 pairs of enantiomers \\
$\mathrm{A}\left(\mathrm{L}_{2}^{1} \mathrm{~L}_{2}^{2}\right) \cdots \mathrm{Nuc}$ & 2 achiral 3 pairs of enantiomers \\
$\mathrm{A}\left(\mathrm{L}_{2}^{1} \mathrm{~L}^{2} \mathrm{~L}^{3}\right) \cdots \mathrm{Nuc}$ & 1 achiral 6 pairs of enantiomers \\
$\mathrm{A}\left(\mathrm{L}^{1} \mathrm{~L}^{2} \mathrm{~L}^{3} \mathrm{~L}^{4}\right) \cdots \mathrm{Nuc}$ & 10 pairs of enantiomers \\
\hline
\end{tabular}

Table 1: Chiral and achiral structures of $\mathrm{A}\left(\mathrm{L}^{1} \mathrm{~L}^{2} \mathrm{~L}^{3} \mathrm{~L}^{4}\right) \cdots \mathrm{Nuc}$ complexes

number of chiral and achiral structures enabled by the nature of the ligands of atom $\mathrm{A}$.

Muetterties has proposed five possible permutation mechanisms enabling ligand interchange in trigonal bipyramidal systems ${ }^{41}$ which are represented in the scheme below in which the central structure corresponds to that of the transition state according to Couzijn et $\mathrm{al}^{43}$.

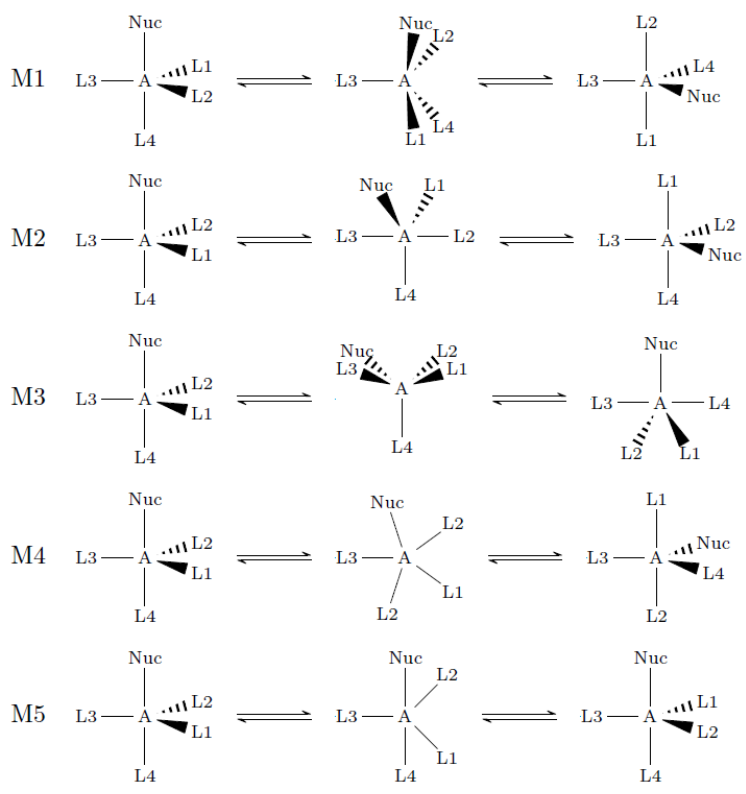

The fist one, denoted by M1 corresponds to the Berry's pseudorotation ${ }^{44}$ puts two axial ligands in equatorial position and two equatorial ligands in axial position. M2 is threefold cyclic permutation of one axial and two equatorial ligands, M3 known as half-twist axial-equatorial interchange which transforms an axial to equatorial ligand. M2 and M3 can be decomposed in two and three Berry type motions ${ }^{43}$. The geometries of transition states are square pyramid for M1 and M3, trigonal bipyramid for M2 and planar (pentahedral) for M4 and M5. The transition states energy barriers reported by Couzijn et al ${ }^{43}$ range from a few kcal. mol ${ }^{-1}$ for the Berry's pseudorotation to about $30 \mathrm{kcal}$. $\mathrm{mol}^{-1}$, i.e. less than the dissociation energy of the central atom-ligand bonds. The planar 
transition states of the M4 and M5 mechanisms implying much more higher barriers, these mechanisms have not been considered.

The isomerism in pentacoordinated complexes involving a secondary bond gives rise to several problems we aim to address in this publication:

1. In the case of an electrophilic reagent possessing several possible electrophilic atomic centres which one is involved in the stablest secondary interaction? in other words is there an energetic hierarchy of secondary interactions

2. Is it possible to have Berry's pseudo rotation in pentacoordinated complexes involving a secondary interaction?

For each question we attempt to formulate simple chemical rules induced from general chemical and quantum chemical experience and literature. These rules are then invalitated or corroborated by numerical experiments carried out on adapted model systems. By numerical experiments it is meant calculations of the properties of real or hypothetical complexes carried out at a realistic level of theory. In almost all systems investigated here ammonia has been chosen as the nucleophile because it yields the largest interaction energy.

\section{Numerical experiment protocol}

The numerical experiments are carried out on complexes of $\mathrm{NH}_{3}$ with model electrophilic molecules. The choice of ammonia as nucleophilic reagent stems from the large complexation energies calculated with this molecule. The building strategy of the electrophile moiety is driven by the specific secondary interactions one can expect or not from simple chemical and structural rules. The only restriction is that the molecule should be stable in its electrophilic model structure. The notation adopted in this article follows the following rules: 1) the secondary interaction is represented by a dot bond line, i. e. $\cdots, 2$ ) the axial ligand bond with $\mathrm{X}$ or $\mathrm{Y}$ by a bond line, 3 ) the equatorial ligands are between parentheses. For example $\mathrm{NH}_{3} \cdots \mathrm{P}\left(\mathrm{OH}_{2}\right)-\mathrm{F}$ denotes the complex of in which the fluorine atom is in axial position and opposed to $\mathrm{NH}$ with respect to the phosphorus centre. The calculations have been performed with the B3LYP ${ }^{45-50}$ hybrid functional with the cc-pVTZ ${ }^{51-53}$ implemented in the Gaussian $09^{54}$ program.

\section{Competitive electrophilic centres}

The general theory of intermolecular forces apply for interactions in the range of those encountered with secondary interactions.

In the case of hydrogen bonding it has been shown that electrostatic contribution to the complexation energy determines the respective orientation of the moieties $^{31,32}$.

The determination of the molecular electrostatic potential of the electrophilic part enable therefore a reliable prediction of the preferred sites of complexation. The first order electrostatic interaction is the dominant factor responsible for the stabilities of the isomers, the second order contributions, the induction and dispersion energies being both attractive bring an extra stabilization energy to 
the stablest isomer which corresponds to the shortest intermolecular distance. The poor evaluation or neglect of dispersion forces in numerical experiment is not expected to alter the relative stability of isomers. However, the induction contributions which account for the deformations of the electron densities upon polarization, may be very important for systems having a negligible dipole moment and a large dipole polarizability. The electron density of the electrophile is governed by the electronegativity of its constituting atoms, the polar character being due to the electron transfers necessary to ensure the electronegativity equalization of the atomic sub parts of the molecule. Therefore electron depletion is expected in the valence shell of the most electropositive atoms suggesting that the stability order follows the group number

$$
\text { tetrel }>\text { pnictogen }>\text { chalcogen }>\text { halogen }
$$

which does not mean that an halogen bond is necessarily weaker than a chalcogen or a pnictogen bond but that in a molecule in which two possible sites are located on bonded atoms belonging to different groups the stablest isomer is that formed on the most electropositive of the two atoms.

\subsection{Halogen-halogen test systems}

Looking for Karl Popper's white ravens ${ }^{55}$ we will first examine the case of systems in which two halogen atoms are in competition. If our statement is true the energy of the isomerization reaction:

$$
\mathrm{H}_{3} \mathrm{~N} \cdots \mathrm{YXO}_{\mathrm{n}} \longrightarrow \mathrm{YXO}_{\mathrm{n}} \cdots \mathrm{NH}_{3}
$$

should be positive for $\chi(\mathrm{Y})<\chi(\mathrm{X})$ and negative for $\chi(\mathrm{Y})>\chi(\mathrm{X})$. Figure 1 displays the isomerization energy as a function of the electronegativity difference.

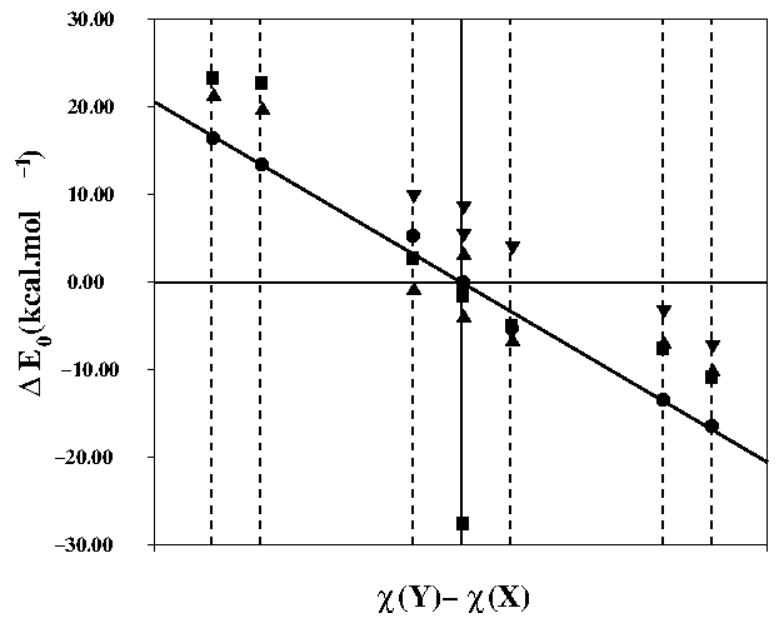

Figure 1: Isomerization energy $\Delta \mathrm{E}_{0}\left(\right.$ in kcal.mol $\left.{ }^{-1}\right)$ vs. electronegativity (Pauling's scale) difference $\chi(\mathrm{Y})-\chi(\mathrm{X}) . \bullet \mathrm{n}=0, \boldsymbol{\square} \mathrm{n}=1, \boldsymbol{\Delta} \mathrm{n}=2, \boldsymbol{\nabla} \mathrm{n} 3$.

For $\mathrm{n}=0$, the isomerization energy appears to be nicely correlated with the electronegativity difference $\left(r^{2}=0.992\right)$. For $\mathrm{n} \neq 0$ the electronegativity model 
works for most systems except on the one hand those with $\mathrm{Y}=\mathrm{X}$ and on the other hand $\mathrm{BrClO}_{2}$ and $\mathrm{ClBrO}_{3}$. The deviation of the $\mathrm{Y}=\mathrm{X}, \mathrm{n} \neq 0$ complexes from the $\mathrm{n}=0$ behaviour is not surprising being the consequence of the different coordination of the two halogen centres.

Indeed, instead of the electronegativity of the element itself, an effective electronegativity value accounting for the coordination of the atom in the molecule and for the electron withdrawing effects of the ligands should be considered.

When the electronegativities of two elements are close, such as those of chlorine and bromine, this effect should be large enough to change the sign of the difference explaining the discrepancies observed for $\mathrm{BrClO}_{2}$ and $\mathrm{ClBrO}_{3}$.

The enhancement of the effective electonegativity of bromine in $-\mathrm{BrO}_{3}$ with respect to $-\mathrm{Br}$ and $-\mathrm{Cl}$ is corroborated by the $\mathrm{YOXO}_{3}$ model systems for which the calculated complexation energies are reported in table 2: $\mathrm{NH}_{3} \cdots \mathrm{ClOBrO}_{3}$ is found stabler than $\mathrm{ClOBrO}_{3} \cdots \mathrm{NH}_{3}$ by 7.0 kcal.mole ${ }^{-1}$ and $\mathrm{NH}_{3} \cdots \mathrm{BrOBrO}_{3}$ stabler than $\mathrm{BrOBrO}_{3} \cdots \mathrm{NH}_{3}$ by 12.8 kcal.mole ${ }^{-1}$.

\begin{tabular}{lcccccc}
\hline $\mathrm{YOXO}_{3}$ & \multicolumn{2}{c}{$\mathrm{YOXO}_{3} \cdots \mathrm{NH}_{3}$} & \multicolumn{3}{c}{$\mathrm{NH}_{3} \cdots \mathrm{YOXO}_{3}$} \\
& $\Delta E_{\mathrm{e}}$ & $\Delta E_{0}$ & $R_{\mathrm{NX}}$ & $\Delta E_{\mathrm{e}}$ & $\Delta E_{0}$ & $R_{\mathrm{NY}}$ \\
\hline $\mathrm{FOClO}_{3}$ & $-3 \cdot 5$ & $-2 \cdot 6$ & $3 \cdot 14$ & $-1 \cdot 3$ & $-0 \cdot 7$ & $2 \cdot 66$ \\
$\mathrm{ClOClO}_{3}$ & $-2 \cdot 9$ & $-2 \cdot 0$ & $3 \cdot 19$ & $-11 \cdot 8$ & $-9 \cdot 6$ & $2 \cdot 28$ \\
$\mathrm{BrOClO}_{3}$ & $-2 \cdot 5$ & $-1 \cdot 7$ & $3 \cdot 22$ & $-17 \cdot 0$ & $-14 \cdot 5$ & $2 \cdot 32$ \\
$\mathrm{FOBrO}_{3}$ & $-7 \cdot 6$ & $-5 \cdot 7$ & $2 \cdot 61$ & $-1 \cdot 7$ & $-1 \cdot 1$ & $2 \cdot 58$ \\
$\mathrm{ClOBrO}_{3}$ & $-6 \cdot 1$ & $-4 \cdot 4$ & $2 \cdot 71$ & $-13 \cdot 1$ & $-10 \cdot 8$ & $2 \cdot 25$ \\
$\mathrm{BrOBrO}_{3}$ & $-5 \cdot 5$ & $-3 \cdot 9$ & $2 \cdot 76$ & $-18 \cdot 3$ & $-15 \cdot 7$ & $2 \cdot 30$ \\
\hline
\end{tabular}

Table 2: Binding energy $\Delta E_{\mathrm{e}}\left(\mathrm{kcal}_{\mathrm{mol}}{ }^{-1}\right)$, ZPE-corrected binding energy $\Delta E_{0}$ (kcal.mol ${ }^{-1}$ ) and internuclear distances $R_{\mathrm{NX}}, R_{\mathrm{NY}}(\AA)$.

\subsection{Halogen-Chalcogen systems and the hydrogen bond- ing possibility}

A next step of validation of our hypothesis is the study of model systems for which $\mathrm{NH}_{3}$ can form a secondary interaction with a chalcogen atom, say $\mathrm{Y}$, or with a halogen centre $\mathrm{X}$. We have considered compounds with $\mathrm{Y}=\mathrm{S}$ and $\mathrm{X}=\mathrm{Br}$ in order to have a small electronegativity difference and thus to expect a small energy difference between the isomers. The complexation energies of the $\mathrm{BrSHO}_{\mathrm{n}}$ complex isomers are reported in table 3.

\begin{tabular}{lccccccccc}
\hline BrSHO $_{\mathrm{n}}$ & \multicolumn{3}{c}{$\mathrm{BrSHO}_{\mathrm{n}} \cdots \mathrm{NH}_{3}$} & \multicolumn{3}{c}{$\mathrm{NH}_{3} \cdots \mathrm{BrSHO}_{\mathrm{n}}$} & \multicolumn{3}{c}{$\mathrm{NH}_{3} \cdots \mathrm{HSBrO}_{\mathrm{n}}$} \\
& $\Delta E_{\mathrm{e}}$ & $\Delta E_{0}$ & $R_{\mathrm{NX}}$ & $\Delta E_{\mathrm{e}}$ & $\Delta E_{0}$ & $R_{\mathrm{NY}}$ & $\Delta E_{\mathrm{e}}$ & $\Delta E_{0}$ & $R_{\mathrm{NY}}$ \\
\hline $\mathrm{BrSH}$ & $-5 \cdot 9$ & $-4 \cdot 4$ & $2 \cdot 70$ & $-4 \cdot 4$ & $-3 \cdot 3$ & $2 \cdot 84$ & $-6 \cdot 1$ & $-4 \cdot 5$ & $2 \cdot 02$ \\
$\mathrm{BrSHO}$ & $-6 \cdot 3$ & $-4 \cdot 9$ & $2 \cdot 84$ & $-2 \cdot 5$ & $-1 \cdot 7$ & $3 \cdot 03$ & $-7 \cdot 5$ & $-6 \cdot 0$ & $2 \cdot 03$ \\
$\mathrm{BrSHO}_{2}$ & $-28 \cdot 2$ & $-27 \cdot 4$ & $2 \cdot 86$ & $-4 \cdot 1$ & $-3 \cdot 2$ & $3 \cdot 16$ & $-11 \cdot 5$ & $-10 \cdot 7$ & $1 \cdot 69$ \\
\hline
\end{tabular}

Table 3: Binding energy $\Delta E_{\mathrm{e}}\left(\mathrm{kcal}_{\mathrm{mol}}{ }^{-1}\right)$, ZPE-corrected binding energy $\Delta E_{0}$ (kcal.mol ${ }^{-1}$ ) and internuclear distances $R_{\mathrm{NX}}, R_{\mathrm{NY}}(\AA)$.

The respective stabilities of the complexes are consistent with the electonegativities of $\mathrm{NH}_{3}$ secondary interaction targets except for $\mathrm{BrSHO}_{2}$. The sulfonyl 
bromide, $\mathrm{BrSHO}_{2}$, molecule has a lower energy functional isomer, the sulfurobromidous acid, in which the hydrogen is bonded to one of the oxygen atoms. We have observed the transposition of the hydrogen atom in the geometry optimization process of the $\mathrm{BrSHO}_{2} \cdots \mathrm{NH}_{3}$ : after few steps the hydrogen distance decreases leading to the $\mathrm{O}-\mathrm{H}$ bond formation. We failed to find a complex involving a secondary interaction directed towards the sulfur centre for the sulfonyl bromide form.

\section{Position isomerism in $\mathrm{AXYH}_{2} \cdots \mathrm{NH}_{3}$ complexes}

The analysis is now extended to the $\mathrm{AX}_{4} \cdots \mathrm{NH}_{3}$ type complexe where the central atom $\mathrm{A}$ is either a group IV or group V element, $\mathrm{X}$ an halogen and $\mathrm{Y}$ another halogen less electronegative than $\mathrm{X}$ or oxygen. The two most stable isomers of both tetrel- and pnictogen-ammonia complexes are illustrated in figure 2 .

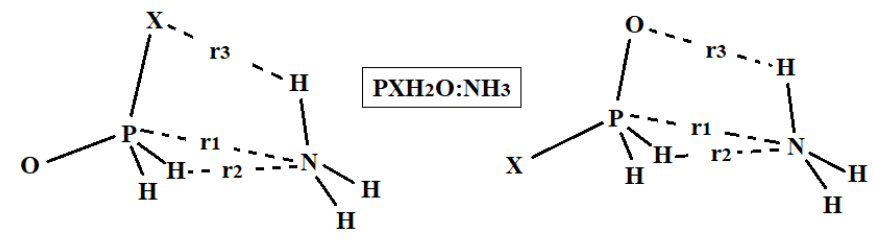

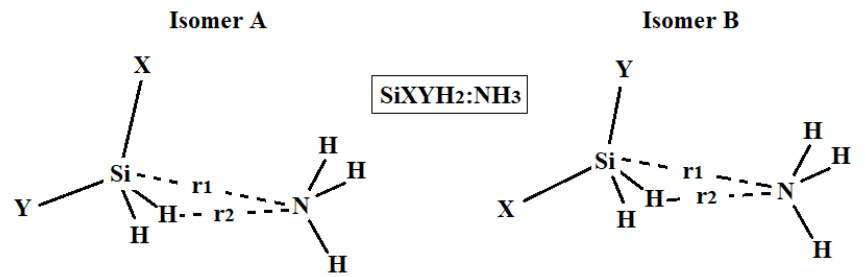

Figure 2: Structural parameters of the two most stable isomers of the $\mathrm{SiXYH}_{2} \cdots \mathrm{NH}_{3}$ and $\mathrm{PXH}_{2} \mathrm{O} \cdots \mathrm{NH}_{3}$ complexes, where $\mathrm{X}=\mathrm{F}, \mathrm{Cl}, \mathrm{Br}$, and $\mathrm{Y}=$ $\mathrm{Cl}, \mathrm{Br}$.

Some relevant data on these complexes are presented in Table 4. It is interesting to note that the secondary interactions between $\mathrm{NH}_{3}$ and phosphorus atom (in the opposite direction to the halogen atom) are slightly more stabilizing (B-isomer) than those between $\mathrm{NH}_{3}$ and $\mathrm{P}$ opposite to $\mathrm{O}$.

As shown by the distances reported in Table 4, the interaction between $\mathrm{NH}_{3}$ and $\mathrm{PXH}_{2} \mathrm{O}$ cannot simply be reduced to a pnictogen $\mathrm{P}-\mathrm{N}$ interaction. Hydrogen-type interaction between the $\mathrm{H}$ atom of $\mathrm{NH}_{3}$ and the halogen centre of $\mathrm{PXH}_{2} \mathrm{O}$ on the one hand, and between the $\mathrm{N}$ atom of $\mathrm{NH}_{3}$ and both $\mathrm{H}^{\prime} \mathrm{s}$ of $\mathrm{PXH}_{2} \mathrm{O}$ on the other hand, also contribute to the stabilization of these complexes. The latter trends also apply to $\mathrm{SiXYH}_{2} \cdots \mathrm{NH}_{3}$ complexes.

Energy decomposition from wavefunction-based Symmetry Adapted Perturbation Theory (SAPT) was carried out on the optimized geometry at SAPT2 +3 level ${ }^{56,57}$ in conjunction with Aug-cc-pVDZ basis set using the Psi4 program. ${ }^{58,59}$. Results gathered in able 5 clearly show that electrostatics contribution is actually cancelled by the exchange repulsion for four studied complexes. The stability of these complexes is essentially due to the polarization contribution, i.e. 


\begin{tabular}{ccccccccccc}
\hline & \multicolumn{4}{c}{ Isomer A } & \multicolumn{4}{c}{ Isomer B } \\
& $\Delta E_{\mathrm{e}}$ & $\Delta E_{0}$ & $r_{1}$ & $r_{2}$ & $r_{3}$ & $\Delta E_{\mathrm{e}}$ & $\Delta E_{0}$ & $r_{1}$ & $r_{2}$ & $r_{3}$ \\
\hline $\mathrm{PFH}_{2} \mathrm{O} \cdots \mathrm{NH}_{3}$ & -7.0 & -5.7 & 3.29 & 2.86 & 2.91 & -8.9 & -7.1 & 2.92 & 2.83 & 2.54 \\
$\mathrm{PClH}_{2} \mathrm{O} \cdots \mathrm{NH}_{3}$ & -4.6 & -3.5 & 3.35 & 2.82 & 3.35 & -6.3 & -4.7 & 2.93 & 2.84 & 2.53 \\
$\mathrm{PBrH}_{2} \mathrm{O} \cdots \mathrm{NH}_{3}$ & -4.7 & -3.6 & 3.34 & 2.80 & 3.44 & -6.5 & -4.9 & 2.93 & 2.84 & 2.54 \\
\hline $\mathrm{SiFClH}_{2} \cdots \mathrm{NH}_{3}$ & -5.0 & -3.2 & 2.75 & 2.72 & & -5.7 & -3.9 & 2.65 & 2.71 & \\
$\mathrm{SiBBrH}_{2} \cdots \mathrm{NH}_{3}$ & -5.0 & -3.2 & 2.75 & 2.71 & & -5.8 & -4.0 & 2.62 & 2.70 & \\
$\mathrm{SiClBrH}_{2} \cdots \mathrm{NH}_{3}$ & -4.4 & -2.9 & 2.93 & 2.81 & & -4.5 & -4.0 & 2.90 & 2.81 & \\
\hline
\end{tabular}

Table 4: Some relevant properties of the two most stable isomers for two complexes $\mathrm{SiXYH}_{2} \cdots \mathrm{NH}_{3}$ and $\mathrm{PXH}_{2} \mathrm{O} \cdots \mathrm{NH}_{3}$, where $\mathrm{X}$ and $\mathrm{Y}=\mathrm{F}, \mathrm{Cl}, \mathrm{Br}$ (see Fig. 2). Energies are given in kcal.mol ${ }^{-1}$ and distances in $\AA$.

the sum of induction and exchange contributions.

\begin{tabular}{lcccc}
\hline Contribution & \multicolumn{2}{c}{$\mathrm{PClH}_{2} \mathrm{O} \cdots \mathrm{NH}_{3}$} & \multicolumn{2}{c}{$\mathrm{SiFClH}_{2} \cdots \mathrm{NH}_{3}$} \\
& Isomer A & Isomer B & Isomer A & Isomer B \\
\hline$E_{\text {elst }}$ & -7.2 & -13.0 & -21.3 & -24.3 \\
$E_{\text {exch }}$ & 7.3 & 14.1 & 26.6 & 32.6 \\
$E_{\text {Coulombic }}=E_{\text {elst }}+E_{\text {exch }}$ & 0.1 & 1.1 & 5.3 & 8.3 \\
$E_{\text {ind }}$ & -1.7 & -3.7 & -7.8 & -9.7 \\
$E_{\text {disp }}$ & -3.8 & -5.4 & -7.1 & -8.6 \\
$E_{\text {Polarization }}=E_{\text {ind }}+E_{\text {disp }}$ & -5.5 & -9.1 & -14.9 & -18.3 \\
\hline
\end{tabular}

Table 5: SAPT energetic contributions $\left(\mathrm{kcal}^{\mathrm{mol}}{ }^{-1}\right)$ for the isomers of the two $\mathrm{SiFClH}_{2} \cdots \mathrm{NH}_{3}$ and $\mathrm{PClH}_{2} \mathrm{O} \cdots \mathrm{NH}_{3}$ complexes.

\subsection{The $\mathrm{PFH}_{2} \mathrm{O} \cdots \mathrm{NH}_{3}$ complex isomers}

According to table 1 , at most 1 achiral form and 6 pairs of enantiomers can be found for the phosphoryl fluoride, $\mathrm{PFH}_{2} \mathrm{O}$, ammonia complex in which the phosphorus centre is penta-coordinated. Howecer, for systems in which the ligands are independent, the isomers are distributed in four achiral forms corresponding with the two hydrogen atoms in equivalent positions and three pairs of enantiomers corresponding to hydrogen atoms in different positions. Only two achiral isomers and a pair of enantiomers have been found to be stable in our calculation, they all correspond to $\mathrm{NH}_{3}$ in axial position. In fact two types of approach can be considered: on the one hand towards the midpoint of each edge of the tetrahedron formed by the ligands and on the other hand towards the centre of the faces. The former approaches which yield in principle to equatorial $\mathrm{NH}_{3}$ isomers do not converge to a local minimum whereas the two chiral isomers are obtained when $\mathrm{NH}_{3}$ is in front ofthe $\mathrm{OHH}$ and $\mathrm{FHH}$ faces and the enantiomers when it is in front of the $\mathrm{OFH}$ and $\mathrm{FOH}$ faces.

The interconversion between the different structures of the phosphoryl fluoride gives rise to four isomerisation reactions for which the transition states have been localized. Figure 3 display ball and stick representation of the ground state isomers and of the transition states for the four reactions.

These reaction have almost the same reaction mechanism: the rotation of 


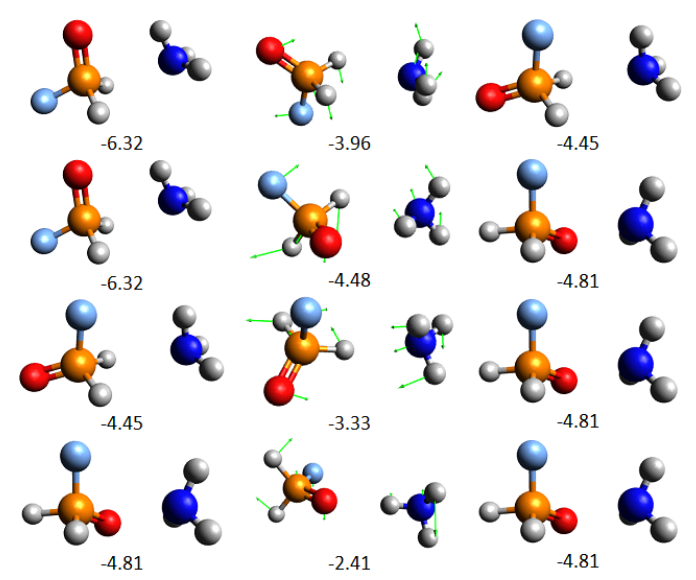

Figure 3: Interconversion of the $\mathrm{PFH}_{2} \mathrm{O} \cdots \mathrm{NH}_{3}$ isomers. The arrows materialize the imaginary frequency mode of the transition state. Second lines: complexation binding energies in Kcal.mol ${ }^{-1}$

the $\mathrm{PFH}_{2} \mathrm{O}$ moiety around its axes perpendicular to the plane formed by the phosphorus atom and the ligands opposed to the ammonia (say L1 and L2) in the reactant the product complexes, respectively. This can be alternatively seen as a bypass of ammonia over the edge formed by L3 and L4, the remaining ligands. Accordingly the reaction is described by the motion of the only nucleophilic moiety with the angle between the L1-P and P-N directions assimilated to the reaction coordinate, $\angle \mathrm{L} 1 \mathrm{PL} 2$ remaining almost constant. This mechanism has nothing to do with those given in the introduction which imply at least the motion of two ligands. It appears, therefore, specific of non-covalent interaction complexes. In all cases investigated here the activation energy is rather small (less than c. a; $2.5 \mathrm{kcal} \mathrm{mole}^{-1}$ ). In the intermolecular forces approach, the repulsive forces between the interacting molecules can be described in terms of more or less sophisticated atom-atom potentials. Considering the repulsive contribution as driving the reaction coordinate, the transition state is expected to correspond to a position of the nitrogen atom in the plane defined by P, L3 and L4 and close to the bisector of $\angle \mathrm{L} 3 \mathrm{PL} 4$.

\section{An empty conclusion}

The deficiencies of the present work are an illustration of the difficulties of the implementation of a numerical experiment strategy inspired by Karl Popper's falsification ideas. Although we have addressed the two questions we failed to design a crucial experiment. Let us consider the two questions successively.

1. The results on the competitive electrophilic centres (section 2.) corroborate the assumption of a hierarchy of secondary interaction. However, it has not been possible to propose a simple chemical rule based on the electronegativity of the element of the electrophilic centre because this latter may be coordinated and therefore an "effective electronegativity" should be considered. 
2. Berry's pseudo rotation as well as the interconversion mechanisms proposed by Muetterties do not apply to the complex we have considered. Although the choice of the $\mathrm{PFH}_{2} \mathrm{O} \cdots \mathrm{NH}_{3}$ complex has been driven by the concern of favouring the Berry's pseudo rotation, as well as we have some arguments against, the only thing which can be said is that pseudo rotation is not the rule in pentacoordinated complexes involving a secondary interaction.

Understanding non covalent interaction is a challenging problem for the computational chemistry community. Our approach of this problem intend to favour "chemical explanations" over "quantum chemical" ones and to corroborate the expectations with numerical experiments. The quality of our results ranges from "not very convincing" to "not so bad", this is not encouraging and question our ability to achieve such a program. However, the demarcation problem flavour of the strategy is so exciting...

\subsection{Supplementary material}

A cartoon of the reaction on top of figure 3 is provided in supplementary material together with the geometries of the isomers and transitions states.

\subsection{DATA AVAILABILITY STATEMENT}

Data available on request from the author.

\section{References}

[1] N.W. Alcock. Secondary bonding to nonmetallic elements. volume 15 of Adv. Inorg. Chem. and Radiochem., pages 1 - 58. Academic Press, 1972.

[2] Henry A. Bent. Structural chemistry of donor-acceptor interactions. Chemical Reviews, 68(5):587-648, 1968.

[3] Ibon Alkorta, José Elguero, and Antonio Frontera. Not only hydrogen bonds: Other noncovalent interactions. Crystals, 10(3):180, 2020.

[4] Peter Politzer and Jane S Murray. A unified view of halogen bonding, hydrogen bonding and other $\sigma$-hole interactions. In Steve Scheiner, editor, NonCovalent forces, chapter 10, pages 291-321. Springer, Cham, Switzerland, 2015.

[5] Pavel Hobza and Zdenek Havlas. Blue-shifting hydrogen bonds. Chem. Rev., 100:4253-4264, 2000.

[6] Benjamin J. van der Veken, Wouter A. Herrebout, Roman Szostak, Dimitrij N. Shchepkin, Zdenek Havlas, and Pavel Hobza. The nature of improper, blue-shifting hydrogen bonding verified experimentally. J. Am. Chem. Soc., 123(49):12290-12293, 2001.

[7] Sofie N. Delanoye, Wouter A. Herrebout, and Benjamin J. van der Veken. Improper or classical hydrogen bonding? a comparative cryosolutions infrared study of the complexes of $\mathrm{HCClF}_{2}, \mathrm{HCCl}_{2} \mathrm{~F}$, and $\mathrm{HCCl}_{3}$ with dimethyl ether. J. Am. Chem. Soc., 124(25):7490-7498, 2002. 
[8] Igor V. Alabugin, Mariappan Manoharan, Scott Peabody, and Frank Weinhold. Electronic basis of improper hydrogen bonding: A subtle balance of hyperconjugation and rehybridization. Journal of the American Chemical Society, 125(19):5973-5987, 2003.

[9] Xiao-Hua Chen, Jie Yu, and Liu-Zhu Gong. The role of double hydrogen bonds in asymmetric direct aldol reactions catalyzed by amino amide derivatives. Chem. Commun., 46:6437-6448, 2010.

[10] Slawomir J. Grabowski. Boron and other triel lewis acid centers: From hypovalency to hypervalency. ChemPhysChem, 15(14):2985-2993, 2014.

[11] Slawomir J. Grabowski. Tetrel bond- $\sigma$-hole bond as a preliminary stage of the $\mathrm{s}_{n} 2$ reaction. Phys. Chem. Chem. Phys., 16:1824-1834, 2014.

[12] S. Zahn, R. Frank, E. Hey-Hawkins, and B. Kirchner. Pnicogen bonds: A new molecular linker? Chem. Eur. J., 17:6034-6038, 2011.

[13] S. Scheiner. A new noncovalent force: Comparison of $\mathrm{p} \cdots \mathrm{n}$ interaction with hydrogen and halogen bonds. J. Chem. Phys., 134:094315, 2011.

[14] W. Wang, B. Ji, and Y Zhang. Chalcogen bond: A sister noncovalent bond to halogen bond. J. Phys. Chem. A, 113, 2009.

[15] Pierangelo Metrangolo, Hannes Neukirch, Tullio Pilati, and Giuseppe Resnati. Halogen bonding based recognition processes: A world parallel to hydrogen bonding. Acc. Chem. Res., 38:386-395, 2005.

[16] A. Bauzá and A. Frontera. Aerogen bonding interactions: A new supramolecular force? Angew. Chem. Int. Ed., 54:7340-7343, 2015.

[17] A. Bauzá and A Frontera. $\sigma-\pi$-hole noble gas bonding interactions: Insights from theory and experiment. Coord. Chem. Rev., 404:213112, 2020.

[18] Akram Mahmudi-Koohi, Zabiollah Mahdavifar, and Siamak Noorizadeh. Can fluorine form halogen bond? investigation of halogen bonds through steric charge. Chemistry Select, 2(9):2713-2717, 2017.

[19] Arpita Varadwaj, Helder M. Marques, and Pradeep R. Varadwaj. Is the fluorine in molecules dispersive? is molecular electrostatic potential a valid property to explore fluorine-centered non-covalent interactions? Molecules, $24: 379,2019$.

[20] Steve Scheiner. F-halogen bond: Conditions for its existence. J. Phys. Chem. A, 124(36):7290-7299, 2020.

[21] H. Margenau. Van der waals forces. Rev. Mod. Phys., 11:1-35, 1939.

[22] Joseph O. Hirschfelder and Robert Silbey. New type of molecular perturbation treatment. J. Chem. Phys., 45:2188-2192, 1966.

[23] J.O. Hirschfelder. Perturbation theory for exchange forces, i. Chem. Phys. Lett., 1:325 - 329, 1967.

[24] J.O. Hirschfelder. Perturbation theory for exchange forces, ii. Chem. Phys. Lett., 1:363 - 368, 1967. 
[25] Ad van der Avoird. Perturbation theory for intermolecular interactions in the wave-operator formalism. J. Chem. Phys., 47:3649-3653, 1967.

[26] J. N. Murrell and G. Shaw. Intermolecular forces in region of small orbital overlap. J. Chem. Phys., 46:1768-1772, 1967.

[27] J. I. Musher and A. T. Amos. Theory of weak atomic and molecular interactions. Phys. Rev., 164:31-43, 1967.

[28] S.T. Epstein and R.E. Johnson. The application of perturbation theories for exchange forces to a simple model. Chem. Phys. Lett., 1:602-604, 1968.

[29] Pierre Claverie. Theory of intermolecular forces. i. on the inadequacy of the usual rayleigh-schrödinger perturbation method for the treatment of intermolecular forces. Int. J. Quant. Chem., 5:273-296, 1971.

[30] P. Claverie. Elaboration of approximate formulas for the interactions between large molecules : Applications in organic chemistry. In B. Pullman, editor, Intermolecular Interactions : From Diatomics to Biopolymers, pages 69-286. Wiley, New York, 1978.

[31] A. D. Buckingham, P. W. Fowler, and J. M. Huston. Theoretical studies of van der waals molecules and intermolecular forces. Chem. Rev., 88:963-988, 1988.

[32] Anthony J. Stone. The Theory of Intermolecular Forces. Oxford University Press, Oxford, second edition edition, 2013.

[33] Timothy Clark, Matthias Hennemann, Jane S. Murray, and Peter Politzer. Halogen bonding: the $\sigma$-hole. J. Mol. Model., 13:291-296, 2007.

[34] Janet E. Del Bene, Ibon Alkorta, and José Elguero. Properties of complexes $\mathrm{H}_{2} \mathrm{C}=(\mathrm{X}) \mathrm{P}: \mathrm{PXH}_{2}$, for $\mathrm{X}=\mathrm{F}, \mathrm{Cl}, \mathrm{OH}, \mathrm{CN}, \mathrm{NC}, \mathrm{CCH}, \mathrm{H}, \mathrm{CH}_{3}$, and $\mathrm{BH}_{2} \mathrm{P} \ldots \mathrm{P}$ pnicogen bonding at $\sigma$-holes and $\pi$-holes. J. Phys. Chem. A, 117(45):1159211604, 2013.

[35] Slawomir J. Grabowski. Triel bonds, $\pi$-hole- $\pi$-electrons interactions in complexes of boron and aluminium trihalides and trihydrides with acetylene and ethylene. Molecules, 20:11297-11316, 2015.

[36] Bernard Silvi, Esmail Alikhani, and Henryk Ratajczak. Towards an unified chemical model of secondary bonding. J. Mol. Mod., 26, FEB 272020.

[37] F. O. Rice and E. Teller. The role of free radicals in elementary organic reactions. J. Chem. Phys., 6:489-496, 1938.

[38] Ronald J. Gillespie and Paul L. A. Popelier. Chemical Bonding and Molecular Geometry. Oxford University Press, Oxford, 2001.

[39] Franck Fuster and Bernard Silvi. Determination of protonation sites in bases from topological rules. Chem. Phys., 252:279-287, 2000. 
[40] Juan Andres, Slawomir Berski, and Bernard Silvi. Curly arrows meet electron density transfers in chemical reaction mechanisms: from electron localization function (ELF) analysis to valence-shell electron-pair repulsion (VSEPR) inspired interpretation. Chem. Commun., 52:8183-8195, 2016. doi: $10.1039 / \mathrm{C} 5 \mathrm{CC} 09816 \mathrm{E}$.

[41] Earl L. Muetterties. Topological representation of stereoisomerism. i. polytopal rearrangements. J. Am. Chem. Soc., 91(7):1636-1643, 1969.

[42] Dorota Krasowska, Jacek Chrzanowski, Piotr Kiełbasinski, and Józef Drabowicz. Chiral hypervalent, pentacoordinated phosphoranes. Molecules, 21:1573, 2016 .

[43] Erik P. A. Couzijn, J. Chris Slootweg, Andreas W. Ehlers, and Koop Lammertsma. Stereomutation of pentavalent compounds: Validating the berry pseudorotation, redressing ugi's turnstile rotation, and revealing the twoand three-arm turnstiles. J. Am. Chem. Soc., 132:18127-18140, 2010.

[44] R. Stephen Berry. Correlation of rates of intramolecular tunneling processes, with application to some group v compounds. J. Chem. Phys., 32 (3):933-938, 1960.

[45] Axel D. Becke. Density-functional thermochemistry. iii. the role of exact exchange. J. Chem. Phys., 98:5648-5652, 1993.

[46] Axel D. Becke. A new mixing of hartree-fock and local density-functional theories. J. Chem. Phys., 98:1372-1377, 1993.

[47] A. D. MacLean and G. S. Chandler. Contracted gaussian basis sets for molecular calculations. i. second row atoms, $\mathrm{z}=11-18$. J. Chem. Phys., 72: $5639-5948,1980$.

[48] R. Krishnan, J. S. Binkley, R. Seeger, and J. A. Pople. Self-consistent molecular orbital methods. xx. a basis set for correlated wave functions. $J$. Chem. Phys., 72:650-654, 1980.

[49] T. Clark, J. Chandrasekhar, G. W. Spitznagel, and Paul von Ragué Schleyer. Efficient diffuse function-augmented basis sets for anion calculations. iii. $^{\dagger}$ the $3-21+\mathrm{g}$ basis set for first-row elements, li-f. $J$. Comput. Chem., 4:294, 1983.

[50] M. J. Frisch, J. A. Pople, and J. S. Binkley. Self-consistent molecularorbital methods. xxv: Supplementary functions for gaussian basis sets. $J$. Chem. Phys., 80:3265-3269, 1984.

[51] Thom H. Dunning Jr. Gaussian basis sets for use in correlated molecular calculations. i. the atoms boron through neon and hydrogen. J. Chem. Phys., 90:1007-1023, 1989.

[52] Rick A. Kendall, Thom H. Dunning Jr., and Robert J. Harrison. Electron affinities of the first -row atoms revisited. systematic basis sets and wavefunctions. J. Chem. Phys., 96:6796-6806, 1992. 
[53] D. E. Woon and T. H. Dunning Jr. Gaussian-basis sets for use in correlated molecular calculations. 3. the atoms aluminum through argon. J. Chem. Phys., 98:1358-1371, 1993.

[54] M. J. Frisch, G. W. Trucks, H. B. Schlegel, G. E. Scuseria, M. A. Robb, J. R. Cheeseman, G. Scalmani, V. Barone, B. Mennucci, G. A. Petersson, H. Nakatsuji, M. Caricato, X. Li, H. P. Hratchian, A. F. Izmaylov, J. Bloino, G. Zheng, J. L. Sonnenberg, M. Hada, M. Ehara, K. Toyota, R. Fukuda, J. Hasegawa, M. Ishida, T. Nakajima, Y. Honda, O. Kitao, H. Nakai, T. Vreven, J. A. Montgomery, Jr., J. E. Peralta, F. Ogliaro, M. Bearpark, J. J. Heyd, E. Brothers, K. N. Kudin, V. N. Staroverov, R. Kobayashi, J. Normand, K. Raghavachari, A. Rendell, J. C. Burant, S. S. Iyengar, J. Tomasi, M. Cossi, N. Rega, J. M. Millam, M. Klene, J. E. Knox, J. B. Cross, V. Bakken, C. Adamo, J. Jaramillo, R. Gomperts, R. E. Stratmann, O. Yazyev, A. J. Austin, R. Cammi, C. Pomelli, J. W. Ochterski, R. L. Martin, K. Morokuma, V. G. Zakrzewski, G. A. Voth, P. Salvador, J. J. Dannenberg, S. Dapprich, A. D. Daniels, Ö. Farkas, J. B. Foresman, J. V. Ortiz, J. Cioslowski, and D. J. Fox. Gaussian 09 Revision D.01, 2009. Gaussian Inc. Wallingford CT 2009.

[55] Karl R. Popper. The Logic of Scientific Discovery. Routledge, London, 2002.

[56] Justin M. Turney, Andrew C. Simmonett, Robert M. Parrish, Edward G. Hohenstein, Francesco A. Evangelista, Justin T. Fermann, Benjamin J. Mintz, Lori A. Burns, Jeremiah J. Wilke, Micah L. Abrams, Nicholas J. Russ, Matthew L. Leininger, Curtis L. Janssen, Edward T. Seidl, Wesley D. Allen, Henry F. Schaefer, Rollin A. King, Edward F. Valeev, C. David Sherrill, and T. Daniel Crawford. Psi4: an open-source ab initio electronic structure program. Wiley Interdisciplinary Reviews: Computational Molecular Science, 2(4):556-565, 2012.

[57] Trent M. Parker, Lori A. Burns, Robert M. Parrish, Alden G. Ryno, and C. David Sherrill. Levels of symmetry adapted perturbation theory (sapt). i. efficiency and performance for interaction energies. The Journal of Chemical Physics, 140(9):094106, 2014.

[58] Justin M. Turney, Andrew C. Simmonett, Robert M. Parrish, Edward G. Hohenstein, Francesco A. Evangelista, Justin T. Fermann, Benjamin J. Mintz, Lori A. Burns, Jeremiah J. Wilke, Micah L. Abrams, Nicholas J. Russ, Matthew L. Leininger, Curtis L. Janssen, Edward T. Seidl, Wesley D. Allen, Henry F. Schaefer, Rollin A. King, Edward F. Valeev, C. David Sherrill, and T. Daniel Crawford. Psi4: an open-source ab initio electronic structure program. Wiley Interdisciplinary Reviews: Computational Molecular Science, 2(4):556-565, 2012.

[59] Robert M. Parrish, Lori A. Burns, Daniel G. A. Smith, Andrew C. Simmonett, A. Eugene DePrince, Edward G. Hohenstein, Uğur Bozkaya, Alexander Yu. Sokolov, Roberto Di Remigio, Ryan M. Richard, Jérôme F. Gonthier, Andrew M. James, Harley R. McAlexander, Ashutosh Kumar, Masaaki Saitow, Xiao Wang, Benjamin P. Pritchard, Prakash Verma, Henry F. Schaefer, Konrad Patkowski, Rollin A. King, Edward F. Valeev, 
Francesco A. Evangelista, Justin M. Turney, T. Daniel Crawford, and C. David Sherrill. Psi4 1.1: An open-source electronic structure program emphasizing automation, advanced libraries, and interoperability. Journal of Chemical Theory and Computation, 13(7):3185-3197, 2017. 